\title{
SUCCESS STORIES IN KNOWLEDGE MANAGEMENT SYSTEMS
}

\author{
Leila Halawi, Embry-Riddle Aeronautical University, halawil@erau.edu \\ Richard McCarthy, Quinnipiac University, Richard.mccarthy@quinnipiac.edu \\ Janine Aronson, University of Georgia, jaronson@uga.edu
}

\begin{abstract}
Historically, information systems have focused on capturing, storing, managing, and reporting explicit knowledge. Organizations today recognize the need to integrate both explicit and tacit knowledge in formal information systems. Knowledge management continues to be a critical strategy for an organization to achieve a sustainable competitive advantage, and consequently succeed in today's knowledge-based economy. Knowledge management systems (KMS) are a class of information systems that manage, store and distribute knowledge. Knowledge management systems have proliferated in practice. In turn, theoretical research on knowledge management and knowledge management systems has proliferated. Knowledge management systems have emerged as powerful sources of competitive advantage. In this paper, we describe the characteristics and concepts of knowledge management systems. We explain how these systems transform modern organizations to high levels of success and present two successful cases that demonstrate this principal. We conclude with a summary of success factors that were common within two successful knowledge management system implementations.
\end{abstract}

Keywords: knowledge management, knowledge management systems, knowledge management success factors, Titan Industries, Siemens.

\section{INTRODUCTION}

Historically, information systems have focused on capturing, storing, managing, and reporting explicit knowledge. Organizations today recognize the need to integrate both explicit and tacit knowledge in formal information systems. Tacit knowledge is viewed merely as knowledge hard to articulate as opposed to articulate, explicit knowledge (Virtanen, 2013; Nonaka and Takeuchi 1995; Baumard 1999; Stewart, 1997). Tacit knowledge is expressed as knowledge that is non-verbalized, instinctive, and implicit (Polanyi, 1967) and has frequently been considered as a significant source for competitive advantage from a resource-based view of the firm (Barney, 1991; Grant, 1996). In contrast, explicit knowledge may be implied and articulated (Simonin, 1999).

Knowledge management is a critical strategy for an organization to achieve a sustainable competitive advantage, and consequently succeed in today's knowledge-based economy. Knowledge management systems (KMS) are a class of information systems that manage, store and distribute knowledge. The simplest KMS do this with explicit knowledge; advanced ones with tacit knowledge. Knowledge management systems have proliferated in practice. In turn, theoretical research on knowledge management and KMS multiplied. Knowledge management systems have emerged as powerful sources of competitive advantage. In his book Knowledge Management Systems, Maier (2003) explains that KMS's definition has many perspectives. He defined a knowledge management system as an ICT platform or application system that integrates and merges functions for handling both explicit and tacit knowledge within an organization. According to Fibycu, Van Way and Charles (2011), a KMS is the suggested workplace connection of precise process phases or domains within a corporation. A KMS can be further defined as an emerging line of systems that centers on generation, collecting, structuring, and distributing an organization's "knowledge" as opposed to "information" or "data." (Singh,2013). Whether attempting to promote KM to senior management or to advise it through one's corporation, it is vital to present valuable case studies and success stories to facilitate and demonstrate to users the applied benefits of KM along with the technology and know-how. In this paper, we describe the basic characteristics and concepts of knowledge management systems. We explain how these systems transform modern organizations leading to high levels of success followed by two successful stories. We conclude with a summary of success factors that were common within two successful knowledge management system implementations. 


\section{LITERATURE REVIEW}

\section{Knowledge Management (KM)}

Large organizations continue to become progressively more alert as to the significance of knowledge for efficiency and competitiveness. The principal cause for this concern with KM is the idea that knowledge and its application are the means by which creativity can be promoted (Nonaka and Nishiguchi, 2000; Nonaka and Takeushi, 1995), innovation facilitated (Hargadon, 1998; Von Krogh, Ichijo and Nonaka, 2000; Hurley and Holt, 1998) pulled in such a way as to advance overall organizational performance whether in the public, private or not-for-profit sectors (Pitt and Clarke, 1999). KM is crucial to organizational survival nonetheless in a complex job involving great outflow of resources (Sedera and Gable, 2010). As such KM continues as an ever more persistent topic within the empirical business community. There is a general acceptance that sustainable competitive advantage in the $21^{\text {st }}$ century will continue to be accomplished thru the deployment of KM. Because of the potential massive returns from KM investment, organizations are not only creating knowledge repositories, but also are completely reorganizing themselves as knowledge-based organizations.

Defining KM is difficult because it has multiple interpretations (Choi, 2000). KM applies systematic approaches to find, understand, and use knowledge to create value (O'Dell, 1996). KM is the systematic, explicit, and deliberate building, renewal, and application of knowledge to maximize an enterprise's knowledge-related effectiveness and returns from its knowledge assets (Wiig, 1997a, b). KM is the formulation of and access to experience, knowledge, and expertise that create new capabilities, enable superior performance, encourage innovation, and enhance customer value (Beckman, 1997). KM is a strategy that turns an organization's intellectual assets, both recorded information and the talents of its members, into greater productivity, new value and increased competitiveness how to produce and optimize skills as a collective entity (Murray, 1998). KM accommodates the critical issues of organizational adoption, survival and competence in face of increasingly irregular environmental change. It represents organizational processes that pursue a synergistic mixture of data and information processing capacity of information technologies, and the creative and innovative capacity of human beings (Malhotra, 1998). Knowledge Management is a mindful strategy of getting the precise knowledge to the correct people at the precise time and helping people share and place information into action in methods that attempt to develop organizational performance (American Productivity Quality Center, 1999). Alavi and Leidner (1999) give a more involved definition of KM as a general and organizationally particular process for acquiring, organizing, and communicating both tacit and explicit knowledge of employees so that others may make use of it to be more effective and productive. KM involves leveraging collective wisdom to accelerate responsiveness and innovation (Frappaolo and Capshaw, 1999). Several valuable concepts are strongly linked to KM. They comprise knowledge assets, tacit and implicit knowledge, best practices that is a group of the most successful solutions, and/or case studies linked to a specific problem or situation in a specific industry, intellectual capital, knowledge system that is a comprehensive system that collects knowledge, stores it in a database, maintains the database, and disseminates the knowledge to users, organizational knowledge base and competitive intelligence (Turban, Rainer \& Potter, 2003). The ability of an organization to learn, develop memory and share knowledge is dependent on its culture (Aronson, 2003).

Information systems has focused on capturing, storing, managing, and reporting explicit knowledge. Organizations today recognize the need to integrate both explicit and tacit knowledge in formal information systems. Big Data repositories have proliferated as a result. Based on Polanyi (1962), two types of knowledge are identified: tacit or implicit knowledge and explicit knowledge. Nonaka and Takeuchi (1995), in The Knowledge Creating Company, provided managers with a framework for distinguishing between explicit or codified (readily accessible and documented) and tacit knowledge (accessible indirectly from human mind) and the conversion processes between them. The four conversion processes they described were: tacit-to-explicit (externalization), explicit-to-explicit (combination), tacit-to-tacit (socialization), and explicit-to-tacit (internalization). Quinn, Anderson and Finkelstein (1996) suggested the following typology based on purpose and use: know-what, know-how, know-where, know-why and care-why.

Tacit knowledge can be explained as experiences, know how, competencies or people skills. It subsists in the form of people skills and competencies and the combined skills which add up to organizational culture (Hall, 1992; Virtanen, 2013). Organizational culture is a division of the tacit knowledge that exists within people. Tacit knowledge 
encompasses two elements: cognitive and technical. Alavi and Leidner (2001) explained that the cognitive aspect includes mental maps, values, perspectives, and paradigms which sum up the mental models of an individual. On the other hand, the whole framework's concrete expertise, crafts, and skills comprise the technical component. As for explicit knowledge, it refers to the knowledge that can be codified and communicated through symbols and/or language (Virtanen, 2013).

Nonaka (1991) emphasized that only human beings can take the role in knowledge creation and that computers are merely tools with great information processing capabilities. The supposition that technology can substitute human knowledge or produce its counterpart has been demonstrated false repeatedly (Davenport and Prusak, 1998). Davenport and Prusak (1998) explain the results of a study illustrating that the launch of Lotus Notes into an organization did not, independently, create a change of information sharing and communication patterns. According to Mahapatra and Sarkar (2000), IT offers a number of functionalities that could enable KM. Table 1 (Mahapatra \& Sarkar, 2000) provides a list of such functions and the IT that supports each function (Appendix).

As information technology advanced, KMS arose to manage the knowledge within an organization. As interest in KMS increased at a rapid pace, recent developments in IT have provided the tools that enable companies to explore KM solutions. A firm's knowledge system consists of several levels of knowledge: individual, group, department, division as well as corporate levels (Roos and von Krogh, 1992).

KMS refer to the use of modern information technologies (e.g., the Internet, intranets, extranets, collaborative computing, software filters, agents, data warehouses) to systematize, enhance and expedite intra- and inter-firm knowledge management (Alavi and Leidner 1999). KMS refer to a class of information systems applied to managing organizational knowledge. They could be IT-based systems developed to support and enhance the organizational processes of knowledge creation, storage/retrieval, transfer and application (Alavi and Leidner 2001).

Knowledge management systems perform four functions:

1. Intermediation: refers to the connection of people to people. Its interpersonal focus positions intermediation within the realm of tacit knowledge.

2. Externalization: refers to the connection of information source to information source. It focuses on explicit knowledge and organizes this knowledge according to some classification framework or ontology.

3. Internalization: refers to the connection of explicit knowledge to people. It involves extracting knowledge from the external repository the filtering.

4. Cognition: which connects knowledge to process. It is the function of systems to make decisions based on available knowledge (Frappaolo and Capshaw, 1999).

With knowledge recognized as the most valuable resource of the organization (Sabri, 2014; Barney, 2001; Drucker, 1993; Barney, 1991; Wernerfelt, 1984), and the positive performance impact of aligning other resources such as those indicated above, proactive managers and executives have learned how to align their knowledge resources with their business strategies. The alignment of the strategies used in managing knowledge with those used in managing business activities is expected to be beneficial for innovation activities and performance (for example, see our cases). One reason for this is that an organization's business strategy (BS) and knowledge strategy (KS) are interdependent. They reinforce each other as they serve the purposes of the organization. For example, BS provides direction and cohesion for the activities of the organization while KS focuses on knowledge, which is the innovation (re-)source for the same organizational activities (Drucker, 1999).

\section{Approaches to Knowledge Management Systems}

There are many different approaches to managing knowledge and building KMS to support the KM process (Earl, 2001). One of the most fundamental dichotomies is the KM strategy adopted by a firm, whether codification or personalization (Hansen, Nohria and Tierney, 1999; Grover and Davenport, 2001). The codification strategy is adopted by companies that manufacture relatively standardized products to fill common needs. This strategy, the process approach, involves carefully coding and storing explicit knowledge in knowledge repositories structured as databases for repetitive use by anyone in the organization. The personalization strategy typically is adopted by companies that provide highly customized solutions to unique problems. For these firms, the practice approach to KM 
is when tacit knowledge is shared mostly through person-to-person contacts, is followed (Turban and Aronson, 2004). Hansen et al. (1999) discovered that firms utilizing knowledge effectively followed one strategy mostly and followed the second strategy to aid the first in an $80 / 20$ split. They also point out that firms that have attempted to balance the two strategies in their knowledge management efforts generally have failed. By reason of their results, the authors stress that competitive strategy guides the choice of a KM strategy.

On the other hand, certain high skilled, research-oriented industries might display traits that entail nearly equal efforts with both approaches. Koenig (2001) contended that the pharmaceutical firms in which he has worked indeed required a 50/50 split. Turban and Aronson (2004) suspect that industries that require both a lot of engineering effort and heavy duty research effort would fit the 50/50 hybrid category where both the process and practice approaches apply.

The role of IT and a KMS in facilitating the transfer of knowledge is central to the success of a codification KM strategy (Alavi and Leidner, 2001; Miles, Miles, Penrone and Edvinson, 1998); while the role of IT may be less central to the success of a personalization strategy (Hansen et al., 1999; Brown and Duguid, 1998; McDermott, 1999). As collaborative computing (IT) tools evolve, the capabilities of personalization strategy KMS improve.

\section{Components of Knowledge Management Systems}

Technology is not a replacement for knowledge. Technology is a channel, a mode, more of a medium for conveying data and information (Spiegler, 2000). Technology can help a company uncover relationships between the tangible and intangible, the tacit and explicit, and the known and the unknown (Silver, 2000). IT does not in itself generate knowledge or assure knowledge generation. Only when decision makers evaluate and develop knowledge management technologies with the organization and culture in mind will those technologies be effective in the transfer and exchange of knowledge among people and between people and systems (Silver, 2000). Technology has been an important factor in knowledge management projects and typically the center of many knowledge management initiatives (Hansen et al., 1999; Ruggles, 1998; Skyrme and Amidon, 1999).

Information Technology (IT) enables every KMS by providing the enterprise architecture upon which it is built (Turban et al., 2003). In the KM context, IT comprises a wide range of applications. KMS are developed using three sets of technologies: (1) communication technologies that allow users to access needed knowledge and to communicate with each other; (2) collaboration technologies that provide the means to perform group work; and (3) storage and retrieval technologies that is using a database management system to store and manage knowledge (Turban and Aronson, 2004). The challenge is to identify and integrate these three technologies to meet the knowledge management needs of an organization.

Tiwana (2000) presented a seven-layer knowledge management architecture. These were the interface layer, the access $\&$ authentication layer, the collaborative intelligence and filtering layer, the application layer, the transport layer, the middleware and legacy integration layer and the repositories. The first layer is the interface between the user and the system. The effectiveness of this layer is the main determinant of the usability of a KMS. The second layer guarantees secure data, control and distribution. The third layer, the collaborative layer, sets the architectural elements of data storage. It catalogs content so as to allow fast retrieval through search tools. The transport layer builds on network infrastructure. The middleware and legacy integration layer ties the KMS to both legacy data and recent data repositories and databases. Table 2 (appendix) presents the seven layers of the knowledge management system architecture (Tiwana, 2000).

\section{Knowledge Management Systems Success}

The view of knowledge as a resource has been widely adopted in the information systems literature as the topic knowledge management. Much of the literature on KM is driven from an information systems perspective and is based on the belief that KMS can be used to capture and store workers' knowledge, and make it available to others through a searchable application (Newell, Swan, Galliers and Scarbrough, 1999). Previous research on KMS is classified based on the elements of evaluation such as a user of KMS, the KMS itself, project, KM process, KM initiative and organization as a whole (Kankanhalli and Tan, 2004). At the user level, there have been studies to evaluate the motivation of users to contribute or seek knowledge from different types of KMS and in a few studies the 
consequent usage of KMS. Table 3 (appendix) lists a sample of the relevant research linking information systems and KMS.

From the research listed in Table 3, we have developed the following short list of demonstrated KM success factors:

- A defined business need. Without this, a system is doomed to failure. It must meet a real business need.

- $\quad$ Strong support from top management. This is necessary to secure funds and other resources to build and maintain the system. It is also necessary to create the environment for the necessary shift in organizational culture. Continued involvement of top management also helps.

- User and management involvement in the development and operational phases, including Communities of Practice (CoP) of users providing and using the knowledge. Involvement leads to user buy in, which leads to the change in organizational culture.

- Sound, reliable technology. If the technology is inappropriate or prone to failure, encouraging users is difficult, if not impossible.

- System ease of use. This encourages users to adopt the system.

- Proper user training. Users must be properly trained or the system will not be trusted and fall into disuse.

- Reward structure for knowledge contributions and use. Knowledge sharing and use become part of everyone's job.

- Successfully demonstrated pilot program to encourage system development and use.

- Demonstrated financial payoff. This encourages continued funding and use. Successful KMS pay for themselves many times over per year once they are deployed. (They may have massive leverage.) The annual return on investment varies by industry and system type. Payoffs of factors on the order of 25 per year $(2500 \%$ per year $)$ are common.

Many of these factors are derived from the general IS success literature (e.g., see Almutairi 2001; Turban \& Aronson, 2004; Watson, et al., 1996).

We now turn to two successful KMS stories that illustrate how KMS succeeds in practice.

\section{KNOWLEDGE MANAGEMENT SYSTEMS SUCCESS STORIES}

\section{Siemens AG}

Siemens AG, a multibillion dollar conglomerate may best be known for its high-speed trains, but also produces everything from x-ray machines to light bulbs to power generation equipment. Siemens is one of the world's largest and most successful companies. Siemens needed to share knowledge more effectively among its nearly half million employees around the globe. In 1996, a group interested in knowledge management organized into a community of interest. They examined how KM, in its infancy, could be exploited at Siemens. These mid-level managers began to develop communities of practice (a $\mathrm{CoP}$ is a group of individuals responsible for creating, refining and maintaining knowledge in its area of expertise, knowledge repositories, and methods to share knowledge (Santosus, 2003). In 1999 , upper management recognized the importance of these efforts. Its central board created a distinct organizational KM unit (Saphörster, 2004).

There were developmental problems, both cultural and technological, which is not unusual when a large-scale IS is proposed. ShareNet provides a database repository, search engine and chat room (Braunstein, 2002). There are online entry forms so that employees may enter knowledge into the repository that they feel may be useful. Employees can then search the repository or browse via topic. Once they find a useful 'nugget,' they may then contact the author(s) for further details. IT is viewed as a tool that enables ShareNet (Knowledge Board, 2002). It is a small portion of the effort. Most of the work involved change management. Siemens internally marketed ShareNet to its employees. There were a hundred internal 'evangelists' who trained and answered questions of employees, and monitored the KMS. Top management supported the entire effort. Incentives are given to employees who provide knowledge to the system. The sales staff quickly learned that the KMS helped them land large contracts readily. 


\section{Issues in Information Systems \\ Volume 18, Issue 1, pp. 64-77, 2017}

As ShareNet evolved, it became an up to date Web-based KMS that provided a valuable knowledge repository available to all employees, thus enhancing global collaboration and competition (Zimmerman, 2003). Other major firms have studied ShareNet before implementing their own KMS. This system has demonstrated through dramatically increased sales that it more than paid for itself several times over every year.

Siemens' success factors demonstrate there was a defined business need, managers and users were involved in its development, user training was carefully designed, there was a reward structure for knowledge contributions, there was a demonstrated financial payoff, and there was strong support from upper management, notably top management. One exception to the way most organizations develop KMS is that the initial interest in developing a KMS was a ground-up phenomenon. This does indeed work, and is a known approach, but for an organization to reap the full benefits of KMS, it must eventually be institutionalized.

\section{Titan Industries}

Titan Industries, Bangalore, India, is the fifth largest integrated watch manufacturer in the world. In addition, through leveraging its manufacturing expertise, Titan has branched into components and subassemblies, machine building and automation solutions, precision engineering for the aerospace and automobile sectors, tooling solutions, electronic sub-assemblies and stylish prescription eyewear. Titan Industries also developed India's largest retail network through its exclusive 'World of Titan', Helios and Fastrack showrooms, after-sales-service centers, jewelry stores, and eyeglass stores. This combination of multi-brand stores, large format stores, precision engineering and fierce competition call for rapid learning throughout the organization (Ramesh, 2010).

Titan Industries continually strives to learn from its past experience to create conditions for future success. Titan continuously identifies factors that aided its success as well as factors that impeded its progress so that its impressive track record is pointing the direction towards future stellar performance. Executive management's investment in the implementation of its corporate-wide Sales and Knowledge Management portal is further evidence.

Early in 2006, Titan's leaders identified two areas of enormous potential to learn from its experiences to build a framework for continued success: knowledge management and sales. Prior to developing its KMS, most internal documents were stored and retrieved manually. There was no standardized workflow for collaboration. Finding information and documents was difficult. Only by institutionalizing its knowledge, could past successes be replicated. Thus, Titan implemented a KM portal as a key component of its business strategy to continue delivering innovative products and services to its customers.

Titan's KM vision is to institutionalize knowledge sharing using portals, communities of practice, and its internal Quest magazine. Titan's KM initiative is a blend of information, collaboration and communication. As part of the development process, Titan mapped knowledge assets and processes for each department. Customer knowledge is also considered important, and thus is captured and used in the sales efforts in other areas.

Enteg Infotech (now Altimetrik) was selected to develop the system (Ramesh, 2010). Enteg used SAP Netweaver's platform to provide flexibility, to fulfill current requirements and lay the foundation for future enhancements. The Net Weaver Portal component provided centralized access to all business-critical SAP and non-SAP applications in one login and user interface. Enteg implemented both the KM and Sales portal with SAP Enterprise Portal 7.0, a component of SAP Netweaver. In addition, custom software was developed to meet unfulfilled business requirements. All employees can share ideas, opinions and knowledge independent of physical location or department base. Decisions are now made on the universal availability of information. Titan expects this availability of information at the finger tips to further accelerate its customer responsiveness to enable it to deliver innovative products and services to its customers. The best feature, according to Titan, is that of managing localized best practices.

The Sales Portal provides management and the sales force with an online sales information tracking tool. Now, Titan can direct appropriate sales activity to the right regions without detracting from other ones. Plus, the manual efforts in tracking sales have been dramatically reduced. Marketing and sales have improved dramatically. 
In its KMS initiative, Titan made it clear that knowledge sharing was an expected part of everyone's job. No rewards or other incentives were created. The culture simply supported and expected it. Titan developed a comprehensive range of metrics covering KM outcomes: deployment, use and effectiveness, though these were not strictly quantifiable.

Communities of Practices (CoPs) at Titan cover activities that include among others retailing, customer service, showroom, maintenance, quality and tool manufacturing. The quality CoP spans functional areas and thus impacts a range of areas in interesting and unanticipated ways. KM CoPs are used by technicians as well as receptionists, and are enhanced during regional and functional meetings.

Titan clearly succeeded in meeting its KMS goal of synergizing knowledge initiatives across diverse sectors. SAP India recognized this project and rewarded Titan with its SAP ACE 2007 award. The Titan success factors are as follows.

Success Factor \#1: A defined business need: For Titan to share knowledge within and across product sets, only a knowledge management system could break down silos that hinder communication and sharing expertise.

Success Factor \#2: Involvement in the system by the managers and users. The communities of practice are the clearest evidence of this. CoPs are the most important mechanism for communication across non-common products. Common areas such as Quality are visible and show the benefits of the system to all users.

Success Factor \#3: The Web interface set a common reference point for all users. Most were familiar with Web access, so training was minimal.

Success Factor \#4: The SAP tools used were sound and proven reliable before system development began.

Success Factor \#5: The very visible Sales Portal had demonstrated success, thus further encouraging its use.

Success Factor \#6: Knowledge sharing is an expected part of everyone's job, and thus part of the culture. True, this was instituted from above; there are many cases where the CEO arranges to get the KMS developed, and then demands its use. The organizational culture then shifts.

Success Factor \#7: There was strong support by the chief executive. He instituted the development of the system and was involved with its development throughout the entire process.

\section{CONCLUSION}

We have described knowledge management and knowledge management systems and focused on relevant success factors. We have provided two case studies that demonstrate how success in practice is described or measured. Early in the development of knowledge management systems, managers and researchers recognized the profound impact that these systems could have on the bottom line. Annual returns ranging from factors of 5 to 25 were routinely attained, depending upon the industry and how well the system was developed and managed (Turban and Aronson, 2004).

While technology is important for KMS implementation, it is clearly not the make or break factor. The behavioral issues are the ones that are critical to KMS success. Like every information system, and especially for large, institutional information systems, defined business needs, executive sponsorship, management and user involvement in development, and user training are critical for KMS success. Other factors of importance include the quality of the knowledge, the quantity of the knowledge, the user interface, the speed of interaction, intention to use, making the system use mandatory and demonstration of payoff. Much of the success of KMS has to do with how well it is advertised internally, that is how well it is marketed internally to the users. They must be sold on the idea to contribute and use the knowledge. Once organizational members buy into the system, success follows providing the system fulfills an important need, because they want it to succeed. System buy in is the secret element of system success. This has been true of any change implemented by any group of human beings. The individuals must consciously own the new system for it to succeed. Otherwise, if forced upon them, it will eventually fail.

From the success stories we find common success factors. Table 1 provides a summary of those factors. 
Issues in Information Systems

Volume 18, Issue 1, pp. 64-77, 2017

Table 1. KMS Common Success Factors

\begin{tabular}{|l|}
\hline KMS FACTOR \\
\hline Senior Management Support \\
\hline A Bottom-up Approach to KMS Development \\
\hline Metrics to Define KMS support \\
\hline A Defined Process to Keep New Knowledge Up-to-Date \\
\hline System Ease of Use \\
\hline
\end{tabular}

This is significant in that in contributes to the literature on knowledge management system success by defining factors that are common in organizations that have achieved successful results. Success stories are vital to demonstrate to organizations considering implementing a KMS system or seeking to implement a knowledge sharing culture across the organization.

\section{REFERENCES}

Alavi, M., \& Leidner, D. E. (1999). Knowledge Management Systems: Issues, Challenges and Benefits. Communications of the Association for Information Systems, 1(7), 2-36.

Alavi, M., \& Leidner, D. E. (2001). Review: Knowledge Management and Knowledge Management Systems: Conceptual Foundations and Research Issues. MIS Quarterly, 25(1), 107-136.

Ali, N., Whiddett, D., Tretiakov, A., \& Hunter, I. (2012). The Use of Information Technologies for Knowledge Sharing by Secondary Healthcare Organisations in New Zealand. International Journal of Medical Informatics, 81(7), 500-506.

Almutairi, H. (2001). Evaluating Information System Success in Public Organizations: A Theoretical Model and Empirical Validation. Doctoral Dissertation: Pennsylvania State University, The Graduate School of Public Affairs, State College, PA.

American Productivity and Quality Center. (1999). Retrieved from http://www.it-consultancy.com/extern/apge.html American Productivity and Quality Center (1999). APQC Benchmarking Study.

Aronson, J. (2003). Knowledge Management. In Turban, Rainer \& Potter (2002).

Barney, J. B. (2001). Is The Resource-Based View A Useful Perspective For Strategic Management Research? Yes. Academy of Management Review, 26(1), 41-56.

Barney, J. B. (1991). Firm Resources and Sustained Competitive Advantage. Journal of Management, 17(1), 99120.

Baumard, P. (1999) Tacit Knowledge in Organizations, London: Sage Publications.

Beckman, T. (1997). A Methodology for Knowledge Management. International Association of Science and Technology for Development AI and Soft Computing Conference: Banff, Canada.

Bock, G., \& Young-Gul, K. (2002). Breaking the Myths of Rewards: An Exploratory Study of Attitudes about Knowledge Sharing. Information Resources Management Journal, 15(2), 14-21.

Bock, G., Shin, K., Suh, A., \& Hu, A. (2009). The Factors Affecting Success of Knowledge-based Systems at the Organizational Level. The Journal of Computer Information Systems, 50(2), 95.

Braunstein, Y. M. (2002). Siemens ShareNet: Building a Knowledge Network. June. people.ischool.berkeley.edu/ bigyale/koethen/km/english/case4.htm. 
Brown, J. S. \& Duguid, P. (2000). The social life of information. Boston, MA: Harvard Business School Press.

Becerra-Fernandez, I., \& Stevenson, J. M. (2001). Knowledge Management Systems \& Solutions for the School Principal as Chief Learning Officer. Mobile: Project Innovation, Inc.

Brown, J. S., \& Duguid, P. (1998). Organizing Knowledge. California Management Review, 40(3), 90-111.

Choi, Y. S. (2000). An Empirical Study of Factors Affecting Successful Implementation of Knowledge Management. Doctoral Dissertation: University of Nebraska, Lincoln, NE.

Constant , D., Sproull, L., and Kiesler, S. (1996). The Kindness of Strangers: The Usefulness of Electronic Weak Ties for Technical Advice. Organization Science, 7(2), 119-135.

Davenport, T. H., De Long, D. W., \& Beers, M. C. (1998). Successful Knowledge Management Projects. Sloan Management Review, 39(2, Winter), 43-57.

Davenport, T. H., \& Prusak, L. (1998). Working Knowledge: How Organizations Manage What They Know. Boston: Harvard Business School Press.

Drucker, P. F. (1993). Post-Capital Society. New York: Harper \& Collins.

Drucker, P. F. (1999). The Coming of the New Organization. Harvard Business Review on Knowledge Management, 124(14), 1-19.

Earl, M. (2001). Knowledge Management Strategies: Toward a Taxonomy. Journal of Management Information Systems, 18(1), 215-233.

Fibuch, E., and Van Way, 3rd, Charles W. (2011). What is a Knowledge Management System and Why Should I Care? Physician Executive, 37(5), 34.

Frappaolo, C., \& Capshaw, S. (1999). Knowledge Management Software: Capturing the Essence of Know-how and Innovations. Records Management Quarterly, 33(3), 44-48.

Grant, R. M. (1996). Prospering in Dynamically Competitive Environments: Organizational Capability as Knowledge Integration. Organization Science, 7, 375-87.

Grover, V., \& Davenport, T. H. (2001). General Perspectives on Knowledge Management: Fostering a Research Agenda. Journal of Management Information Systems, 18(1), 5-21.

Halawi, L. A., McCarthy, R. V., \& Aronson, J. E. (2008). An Empirical Investigation of Knowledge Management Systems Success. The Journal of Computer Information Systems, 48(2), 121-135.

Hall, R. (1992). The Strategic Analysis of Intangible Resources. Strategic Management Journal, 13, 135-144.

Hansen, M. T., Nohria, N., \& Tierney, T. (1999). What's Your Strategy for Managing Knowledge? Harvard Business Review, 77(2), 106-118.

Hargadon, A. B. (1998). Firms as Knowledge Brokers: Lessons in Pursuing Continuous Innovation. California Management Review, 40(3), 209-227.

Hurley, R.F. \& Hult, G.T.M. (1998), “'Innovation, Market Orientation, and Organizational Learning: An Integration and Empirical Examination. Journal of Marketing, 62(3), 42-54. 


\section{Issues in Information Systems}

Volume 18, Issue 1, pp. 64-77, 2017

Jarvenpaa, S. L., \& Staples, D. S. (2000). The Use of Collaborative Electronic Media for Information Sharing: An Exploratory Study of Determinants. Journal of Strategic Information Systems, 9, 129-154.

Jennex, M. E., \& Olfman, L. (2003). A Knowledge Management Success Model: An Extension of DeLone and McLean's IS Success Model. Proceedings of the 9th Americas Conference on Information Systems, AMCIS, Tampa, FL.

Kanhanhalli, A., \& Tan, B. C.Y (2004). A Review of Metrics for Knowledge Management Systems and Knowledge Management Initiatives. Proceedings of the 37th Hawaii International Conference on System Sciences, Big Island, Hawaii.

Khalifa, M., Yan Yu, A., \& Ning Shen, K. (2008). Knowledge Management Systems Success: A Contingency Perspective. Journal of Knowledge Management, 12(1), 119-132.

Knowledge Board. (2002). Case Study: The Siemens ICN Knowledge Management Challenge: ICN/ICM ShareNet. Oct. 7.

Koenig, M. (2001, Sept.). “Codification vs. Personalization.” KMWorld.

Mahapatra, R. K., \& Sarkar, S. (2000). The Role of Information Technology in Knowledge Management. AMCIS 2000 Proceedings, Long Beach, CA.

Malhotra, Y. (1998). Knowledge Management for the New World of Business. Global Risk Management Network, Ithaca, NY. Retrieved from http://www.brint.com/km/whatis.htm.

Maier, R. (2003). Knowledge Management Systems: Information and Communication Technology for Knowledge Management. Berlin: Springer.

McDermott, R. (1999). Why Information Technology Inspired But Cannot Deliver Knowledge Management. California Management Review, Summer 41(4), 103-117.

Miles, G., Miles, R. E., Perrone, V., \& Edvinsson, L. (1998). Some Conceptual and Research Barriers to the Utilization of Knowledge. California Management Review, 40(3), 281-288.

Murray, P. C. (1998). New Language for New Leverage. The Terminology of Knowledge Management. CorporateEducation. Biz, LLC, NY. Retrieved from http://www.ktic.com/topic6/13_term2.htm.

Newell, S., Swan, J., Galliers, R. D., \& Scarbrough, H. (1999). The Intranet as a KM Tool? Creating Electronic Fences. Information Resource Management Association, International Conference, Effective Utilization and Management of Emerging Information Technologies, May, N., USA.

Nonaka, I. (1991). The Knowledge Creating Company. Harvard Business Review, 69(6), 96-104.

Nonaka, I., \& Nishiguchi, T. (2000). In Nonaka, I. \& Nishiguchi, T. (Eds.), Knowledge Emergence: Social, Technical, and Evolutionary Dimensions of Knowledge Creation. New York: Oxford University Press,.

Nonaka, I., \& Takeuchi, H. (1995). The Knowledge-Creating Company: How Japanese Companies Create the Dynamics of Innovation. New York: Oxford Press.

O'Dell, C. (1996). A Current Review of Knowledge Management Best Practice. Conference on Knowledge Management and the Transfer of Best Practices. Business Intelligence: London..

Pitt, M., and Clarke, K. (1999). Competing on Competence: A Knowledge Perspective on the Management of Strategic Innovation. Technology Analysis \& Strategic Management, 11(3), 301-316. 
Polanyi, M. (Ed.) (1962). Personal Knowledge. Chicago: University of Chicago Press.

Polanyi, M. (1967). The Tacit Dimension. Garden City, NY: Anchor

Quinn, J. B., Anderson, P., and Finkelstein, S. (1996). Managing Professional Intellect: Making the Most of the Best. Harvard Business Review, 74(2), 71-82.

Rao, M. (2010), Case Study: Knowledge Management at Titan Industries, The KM Chronicles at http://kmtechsparks.com, 2010.

Ramesh, C.S., Enteg Implements Knowledge and Sales Portal at Titan Industries, http://www.enteg.com/newsletter/custom_titan_km.html, Enteg, Bangalore, India, 2010. Titan Industries, http://www.titanworld.com, Bangalore, India, 2011.

Roos, J., \& von Krogh, G. (1992). Figuring out Your Competence Configuration. European Management Journal, $10(4), 422-444$.

Ruggles, R. (1998). The State of Notion: Knowledge Management in Practice. California Management Review, $4(3), 80-89$.

Sabri, A. (2014). Applying DeLone and McLean IS Success Model on Sociotechno-knowledge Management Systems. International Journal of Computer Science Issues, 11(6), 160

Santosus, M. (2003). How Siemens Keeps KM Blooming. In the Know at CIO.com. CIO.com. February.

Saphörster, S. (2004). Knowledge Management, Siemens AG. Spring.

Sedera, D., \& Gable, G. G. (2010). Knowledge Management Competence for Enterprise System Success. Journal of Strategic Information Systems, 19(4), 296-306.

Shih-Chen, L., Lorne, O., \& Terry, R. (2005). Knowledge Management System Success: Empirical Assessment of a Theoretical Model. International Journal of Knowledge Management, 1(2), 68-87.

Silver, C. A. (2000). Where Technology and Knowledge Meet. The Journal of Business Strategy, Nov./Dec. 21(6), 28-33.

Simonin, B. L. (1999). Ambiguity and the Process of Knowledge Transfer in Strategic Alliances. Strategic Management Journal, 20(7), 595-623.

Singh, J. (2013). Practicing Knowledge Management System. International Journal of Information, Business and Management, 5(4), pp 209.

Skyrme, D. J., \& Amidon, D. M. (1999). The Knowledge Agenda. In: Cortada, J. W., \& Woods, J. A. (Eds.), The Knowledge Management Yearbook 1999-2000. Boston, MA: Butterworth-Heinemann; 109-126.

Spiegler, I. (2000). Knowledge Management: A New Idea or a Recycled Concept? Communications of the Association for Information Systems, 3(14).

Stewart, T. (1997), Intellectual Capital: The New Wealth of Organizations. New York: Doubleday

Tiwana, A. (2000). The Knowledge Management Toolkit: Practical Techniques for Building a Knowledge Management System. Upper Saddle River, NJ: Prentice Hall. 
Turban, E., \& Aronson, J. E. (2004). Decision Support Systems and Intelligent Systems. 7th Edition, Upper Saddle River, NJ: Prentice Hall.

Turban, E., Rainer, R. K., \& Potter, R. E. (2003). Introduction to Information Technology. 2nd Ed., New York: John Wiley \& Sons Inc.

Von Krogh, G., Ichijo, K.,\& Nonaka, I. (2000). Enabling Knowledge Creation: How to Unlock the Mystery of Tacit Knowledge and Release the Power of Innovation. New York: Oxford University Press.

Virtanen, I. (2013). In Search for a Theoretically Firmer Epistemological Foundation for the Relationship between Tacit and Explicit Knowledge. Electronic Journal of Knowledge Management, 11(2), pp 118.

Wasko, M. M., \& Faraj, S. (2000). It is What One Does: Why People Participate and Help Others in Electronic Communities of Practice. Journal of Strategic Information Systems, 9, pp 155-173.

Watson, H. J., Aronson, J. E. , Hamilton, R. H., Iyer, L. S., Nagasundaram, M., Nemati, H.R., \& Suleiman, J. (1996) Assessing EIS Benefits: A Survey of Current Practices, Journal of Information Technology Management, 7(1\&2), 23-30.

Wernerfelt, B. (1984). A Resource-Based View of the Firm. Strategic Management Journal, 5, pp 171-180.

Wiig, K. (1997a). Knowledge Management: An Introduction and Perspective. Journal of Knowledge Management, 1(1), pp 6-14.

Wiig, K. M. (1997b). Knowledge Management: Where Did it Come From and Where Will It Go? Expert Systems with Applications, 13(1), 1-14.

Wu, J., \& Wang, Y (2006). Measuring KMS Success: A Respecification of the DeLone and McLean's Model. Information \& Management, 43, pp 728-739.

Zimmerman, K.A. (2003). Happy Together: Knowledge Management and Collaboration Work Hand-in-Hand to Satisfy the Thirst for Information. KM World. May. 


\section{APPENDIX}

Table 1. IT Functions (Mahapatra \& Sarkar, 2000)

\begin{tabular}{|ll|}
\hline Functionality & Technology \\
\hline Communication & Email, Video conferencing \\
\hline Coordination & Email, Scheduling software \\
Group process support & Groupware \\
Storage and Retrieval & Database management, Information Retrieval, \\
& Hypertext, Internet and Intranet \\
Browsing & GUI, Web Browser \\
Presentation & Presentation software \\
Numerical Computation & Statistical analysis packages, Computational algorithms \\
Location, filtering & Intelligent agents \\
Symbolic processing and reasoning & AI, Expert Systems. \\
\hline
\end{tabular}

Table 2. The Seven Layers of the KMS Architecture (Tiwana, 2000)

\begin{tabular}{|l|l|}
\hline Interface layer & Browser \\
\hline Access and authentication layer & $\begin{array}{l}\text { Authentication, recognition, security, firewall and } \\
\text { tunneling. }\end{array}$ \\
\hline Collaborative intelligence and filtering layer & $\begin{array}{l}\text { Intelligent agent tools, content personalization, } \\
\text { search, indexing and metatagging. }\end{array}$ \\
\hline Application layer & $\begin{array}{l}\text { Skills directories, yellow pages, collaborative work } \\
\text { tools, rationale capture tools, DSS tools, and GDSS } \\
\text { tools. }\end{array}$ \\
\hline Transport layer & $\begin{array}{l}\text { Web and TCP/IP deployment, streaming audio, } \\
\text { document exchange, video transport, VPN core, } \\
\text { electronic mail and POP/SMTP support. }\end{array}$ \\
\hline Middleware and legacy integration layer & $\begin{array}{l}\text { Wrapper tools (such as TCL/TK or scripts to } \\
\text { integrate legacy or cross-platform data). }\end{array}$ \\
\hline Repositories layer & $\begin{array}{l}\text { Legacy, data warehouse, discussion forums, } \\
\text { document bases and others. }\end{array}$ \\
\hline
\end{tabular}


Table 3. Research on Information Systems \& Knowledge Management Systems

\begin{tabular}{|l|l|}
\hline Category & Paper \\
\hline KMS & Alavi \& Leidner (1999) \\
\hline KMS Classification & Becerra-Fernandez \& Stevenson (2001) \\
\hline Information Systems Success & Almutairi (2001) \\
\hline Knowledge Contributor & Wasko \& Faraj (2000) \\
\hline Contributing Factors on Knowledge Seeker & Constant, Sproull \& Kiesler (1996) \\
\hline Knowledge Contributor \& Seeker Combined & Jarvenpaa \& Staples (2000) \\
\hline KMS User Study & Bock \& Gul-Kim (2002) \\
\hline KMS Success & Jennex \& Olfman (2003) \\
& Khalifa, Yan Yu, \& Ning Shen (2008) \\
\hline KMS Success Model & Ali, Tretiakov, \& Whiddett (2014) \\
& Shih-Chen, Lorne, \& Terry (2005) \\
& Bock, Suh, Chin \& Hu (2009) \\
\hline KM Projects & Ruggles (1998) \\
& Skyrme \& Amidon (1999) \\
& Davenport \& Prusak (1998) \\
& Davenport, DeLong \& Beers (1998) \\
\hline KMS Success \& DeLone & Halawi, McCarthy \& Aronson (2006) \\
& Sabri (2014) \\
& Wu \& Wang (2006) \\
\hline
\end{tabular}

